\title{
Preventive Effects of Alpha-Lipoic Acid on Lipopolysaccharide- Induced Endothelial Dysfunction in Rats
}

\author{
${\text { Fransiska Maria Christianty }{ }^{1 *} \text {, Suharjono }}^{2}$, Imam Susilo ${ }^{3}$, Junaidi Khotib ${ }^{2}$ \\ ${ }^{1}$ Departement of Clinical and Community Pharmacy, Faculty of Pharmacy, University of Jember, Jember, East Java, Indonesia \\ ${ }^{2}$ Departement of Clinical Pharmacy, Faculty of Pharmacy, Airlangga University, Kampus C, Surabaya, East Java, Indonesia \\ ${ }^{3}$ Departement of Pathological Anatomy, Faculty of Medicine, Airlangga University, Kampus A, Surabaya, East Java, Indonesia
}

\begin{abstract}
Endothelial dysfunction has been considered as one of the key initial events in the pathogenesis of atherosclerosis and other cardiovascular diseases (CVDs). Several studies imply that chronic inflammation and oxidative stress play a critical role in endothelial dysfunction. The present study was designed to evaluate the preventive effect of alpha-lipoic acid (ALA) on lipopolysaccharide (LPS) induced endothelial dysfunction in rat based on malondialdehyde (MDA) level and vascular cell adhesion molecules-1 (VCAM-1) expression. Thirty Wistar rats were administered ALA for 2 weeks in different doses $\left(30,60,120\right.$ mg.kg-1 BW) 1 hour before LPS 0.5 mg. $\mathrm{kg}^{-1} \mathrm{BW}$ i.p challenge. The LPS was injected on $1^{\text {st }}, 4^{\text {th }}$, and $9^{\text {th }}$ day. MDA plasma level was analyzed with spectrophotometer $\lambda 529 \mathrm{~nm}$, and VCAM-1 expression was determined by immunohistochemistry. Pretreatment with ALA for 14 days could decrease plasma MDA level on LPS-induced endothelial dysfunction in rats. However, only one group of ALA doses, $120 \mathrm{mg} \cdot \mathrm{kg}^{-1} \mathrm{BW}$, showed significant difference with LPS untreated group statistically. It was also found that ALA, in all treatment groups, could attenuate VCAM-1 expression. These findings suggest that ALA had a protective effect against endothelial dysfunction and may potentially prevent vascular inflammatory disease.
\end{abstract}

Keywords: alpha lipoic acid; lipopolysaccharide; endothelial dysfunction; MDA; VCAM-1

*corresponding author

Email: fransiska.farmasi@unej.ac.id

\section{INTRODUCTION}

Cardiovascular diseases (CVDs) are a group of disorders or conditions affecting the heart and vascular diseases of the brain or blood vessels. According to the WHO facts sheet, $31 \%$ of all global deaths were mainly caused by CVDs more than any other cause. It was estimated that 17.9 million people died from CVDs in 2016. Of these deaths, $85 \%$ are due to heart attack and stroke. More than $75 \%$ of CVD deaths occur in low-income and middleincome countries (WHO, 2014). In Indonesia, the proportional mortality caused by CVD reached $>35 \%$ in 2016 (WHO, 2018).

The disorders in the cardiovascular system begin with endothelial dysfunction. Endothelial dysfunction is the early predictor of atherosclerosis (Mudau et al., 2012). Cardiovascular risk factors such as hypertension, dyslipidemia, diabetes, inflammation, obesity, and smoking also lead to endothelial dysfunction and contribute to the disease progression (Munzel et al., 2010; Favero et al., 2014). The characteristics of that condition are the increasing of endothelial permeability and production of inflammatory mediators, such as a cytokine, chemokine, and adhesion molecule, especially Vascular Cell Adhesion Molecule-1 (VCAM-1). Endothelial dysfunction is followed by platelet activation, smooth muscle cell proliferation and migration (Favero et al., 2014; Liu et al., 2012; Steyers and Miller, 2014; Gimbrone and García-Cardeña, 2016). All of them can cause the development of atherogenesis, and they are responsible for the death caused by CVDs (Munzel et al., 2010, Wang \& Huo, 2010).

Furthermore, oxidative stress is also responsible for inducing endothelial dysfunction. Oxidative stress means a condition in which cells are exposed to reactive oxygen species (ROS) in excessive level. The molecule acts as a messenger molecule that involves vascular inflammation (George \& Lyon, 2010; Widlansky \& Gutterman, 2011). Malondialdehyde (MDA) is a lipid peroxidation product caused by excessive ROS involved in the pathophysiology of endothelial dysfunction. The previous study showed a positive correlation between MDA and atherogenic index in hyperlipidemia (Yang et al., 2008), preeclampsia (Bharadwaj et al., 2014), and sickle cell nephropathy (Emokpae and Uadia, 2012).

In recent years, antioxidants become one of therapeutic approach to improve endothelial function in preventing CVDs. Alpha-lipoic acid (ALA), also known as lipoic acid is a dithiol compound that acts as an antioxidant. It is synthesized from octanoic acid enzymatically in the mitochondrion. It has a role in energy metabolism as a 
cofactor for mitochondrial $\alpha$-ketoacid dehydrogenases. It is now marketed widely and has much potential health benefits, especially for preventing diabetic polyneuropathy by improving motor nerve conduction of upper and lower extremities (Vijayakumar et al., 2014). ALA provided a significant improvement in the manifestations of diabetic sensorimotor polyneuropathy (McIlduff \& Rutkove, 2011). Ying et al. (2010) reported that in vitro, ALA was able to inhibit nuclear factor kappa B (NF- $\mathrm{kB})$ activation, to decrease oxidative stress and expression of adhesion molecules in atherosclerosis model.

Furthermore, ALA improved cardiac function, attenuated VCAM-1 expression and leukocyte migration in myocardial through phosphoinositol-3Akt (PI3Akt) dependent pathway (Jiang et al., 2013). Unfortunately, there were only a few studies about ALA on lipopolysaccharide (LPS)-induced endothelial dysfunction in rats, especially in a constant challenge. Therefore, this present study was designed to evaluate the effectiveness of ALA on LPS-induced endothelial dysfunction.

\section{METHODS}

\section{Materials}

Alpha-lipoic acid (ALA) as a sample was obtained from Dexa Medika (Palembang, Indonesia). LPS $E$. coli 055: B55 and 2-Thiobarbituric acid (TBA) were purchased from Sigma-Aldrich (St. Louis, MO, USA). VCAM-1 antibody, sc-1504 was obtained from Santa Cruz Biotechnology (Santa Cruz, CA, USA) and kit for immunohistochemistry was purchased from Biocare Medical (USA). Trichloroacetic acid (TCA), $\mathrm{NaOH}, \mathrm{HCl}$ (Merck, Jakarta, Indonesia), and tetra ethoxy propane (TEP) (TCI, Tokyo, Japan) were used for determining the level of MDA plasma and other reagents, such as diethyl ether, propylene glycol, aqua dest, and formaldehyde were purchased from Bratachem (Surabaya, Indonesia).

\footnotetext{
Animals

Adult male Wistar rats (150-250 g), 2-3 months of age, healthy were procured from Faculty of Pharmacy, Airlangga University, Surabaya, Indonesia and were housed in suitable cages per group $(n=6)$ at an ambient temperature $\left(25 \pm 2^{\circ} \mathrm{C}\right)$, relative humidity $(50 \pm 5 \%)$, with a 12:12 h light-dark cycle (lights on at 07.00 am until $7.00 \mathrm{pm})$. Animals had free access to standard pellet chow (Japfa Comfeed Indonesia, Surabaya, Indonesia) and drinking water. All animals were adapted for a week in the laboratory. The Animal Ethics Committee, Faculty of Veterinary, Airlangga University, Surabaya, Indonesia has approved this experimental procedure, with document number: 433-KE.
}

\section{Experimental Protocol}

Thirty rats were randomly assigned to 5 groups. Rats in the healthy group received saline i.p. injection, whereas LPS group and all of the treatment groups were induced with LPS 0.5 mg. $\mathrm{kg}^{-1} \mathrm{BW}$ in saline i.p, three times induction, once in every three days $\left(1^{\text {st }}, 4^{\text {th }}\right.$, and $9^{\text {th }}$ day). One hour before LPS induction, both the healthy and LPS groups received propylene glycol 50\% 1mL/day per oral, whereas the treatment groups received ALA in different doses, $30 \mathrm{mg} \cdot \mathrm{kg}^{-1} \mathrm{BW}, 60 \mathrm{mg} \cdot \mathrm{kg}^{-1} \mathrm{BW}$, and 120 mg. $\mathrm{kg}^{-1} \mathrm{BW}$ per oral. Both ALA or $50 \%$ propylene glycol was administered every day for 14 days ( $1^{\text {st }}$ day to $14^{\text {th }}$ day). On the $15^{\text {th }}$ day, surgery was performed, and blood plasma was collected for determining MDA level. The aortic incision preparation was also obtained and prepared by immunohistochemistry method to measure the VCAM-1 expression.

\section{Determination of plasma MDA level}

A volume of $0.5 \mathrm{ml}$ plasma was pipetted and put in a 10 $\mathrm{mL}$ test tube, then added with $0.5 \mathrm{ml}$ TCA to precipitate the protein. Briefly, $1 \mathrm{ml}$ Sodium-TBA $1 \%$ and $\mathrm{HCl} \mathrm{0,1} \mathrm{N}$ were also added until getting $10 \mathrm{~mL}$ solution. They were mixed then heated up in a water bath at $90^{\circ} \mathrm{C}$ for $30 \mathrm{~min}$. Then all the tubes were rapidly cooled and centrifuged at $3000 \mathrm{rpm}$ for $15 \mathrm{~min}$. All procedure for determining plasma MDA level used Thiobarbituric acid-reactive substances (TBARS) methods. The absorbance of the pink solution was measured photometrically using spectrophotometer UV Vis at $529 \mathrm{~nm}$. The concentration was expressed as $\mu \mathrm{mol} / \mathrm{L}$.

\section{Immunohistochemistry and scoring of VCAM-1 expression}

Aortic tissue was fixed in 10\% formaldehyde for a minimum of 24 hours. Then it was embedded in paraffin wax and was sliced at $4 \mu \mathrm{m}$ thickness. It was incubated overnight in $4^{\circ} \mathrm{C}$ with rat antibody VCAM1. The expression of VCAM-1, appeared dark brown on the surface of endothelial cells, was observed using Light Microscope (Olympus BX53 with camera DP21) and scored using the Allred system. It was calculated by combining the proportion of positive cells and the intensity of the reaction product in most of the examined field. The two scores are then added together to get a final score with eight possible values (Allred, 2005).

\section{Statistical analysis}

The results of MDA level data were presented as means \pm standard deviation $(\overline{\mathrm{x}} \pm \mathrm{SD})$. Between-group comparisons were performed using one-way analysis of variance (ANOVA), followed by Tukey's procedure for multiple range tests. Scoring of VCAM-1 expression was analyzed with Kruskal-Wallis, continued with Mann-Whitney test. A value of $\mathrm{p}<0.05$ was considered significant. 


\section{RESULTS AND DISCUSSION}

Endothelial dysfunction breaks the mechanism of vascular homeostasis regulation. It results in vasoconstriction in the blood vessel wall, leading to leukocyte migration and adhesion. It also promotes the activation of platelet, thrombosis, coagulation, oxidative stress, and inflammation then lead to the pathogenesis of cardiovascular diseases (Favero et al., 2014). Endothelial dysfunction has been assumed as one of the critical initial events in the pathogenesis of atherosclerosis and responsible for the death caused by CVDs (Wang \& Huo, 2010).

Since LPS can induce inflammation in the vascular wall through direct activation of resident cells such as endothelial cells, this experimental model can be used to cause endothelial dysfunction. The circulating cytokines or other inflammatory mediators that are produced by LPS also develop sickness behaviour syndrome and oxidative stress in rat that can be protected with COX inhibitors (Jayashree \& Prakash, 2015). LPS from E.coli has high toxicity. It is often considered as the most potent initiator for activating monokines. The structure of Hexa-acyl diphosphorylated lipid A with acyl chains of length C12-C14 is widely believed to the structure optimally configured to stimulate maximal activation of toll-like receptor-4 (TLR-4). This complex will then lead to monocyte activation (Erridge et al., 2002). In vivo, LPS E. coli (0.05 mg. $\mathrm{mL}^{-1}$ LPS in PBS or $0.5 \mathrm{mg} . \mathrm{kg}^{-1} \mathrm{BW}$ i.p) could induce endothelial dysfunction in 24 hours through increasing protein expression in endothelial cells, such as LOX-1, NFkB, and p38- mitogen-activated protein kinase (MAPK) (Zhao et al., 2014). The LPS-mediated inflammatory environment also affects iNOS, TNF $\alpha$ and IL-6 mRNA levels in a concentration-dependent manner (Baek et al., 2018). Since it was known that LD50 of $E$. coli LPS i.p in the rat is $5 \mathrm{mg} \cdot \mathrm{kg}^{-1} \mathrm{BW}$, and minimum dose $1 \mathrm{mg} \cdot \mathrm{kg}^{-1} \mathrm{BW}$ still caused some deaths in 24 hours (Ashour et al., 2011), thus in this present study LPS dose $0.5 \mathrm{mg} . \mathrm{kg}^{-1} \mathrm{BW}$ was used. Three times inductions, once in every three days, are being considered to obtain the persistent effect of endothelial dysfunction.

\section{Effect of ALA on plasma MDA level}

A growing body of evidence suggests that increased production of ROS can induce endothelial dysfunction (Munzel et al., 2010). LPS-induced rabbits showed increased production of protein oxidation (carbonyl) and lipid peroxidation (MDA \& 4-hydroxy alkene) both in tissue or plasma (Gonzalo et al., 2010). The mechanism explained that a complex of LPS/TLR-4 would trigger intracellular ROS production mediated by NADPH oxidase and through activation $\mathrm{NFKB}$ and MAPK pathway will induce the increasing of pro-inflammatory mediators. The increasing of MDA level will reduce endothelial function (Lee et al., 2012).

The result of this study showed that three times inductions of LPS $0.5 \mathrm{mg} \cdot \mathrm{kg}^{-1}$ BW i.p, once in every three days induced oxidative stress as shown by significant increase of MDA level $(\mathrm{p}<0,001)$, almost two folds compared to the healthy group. Treatment with ALA at a dose $30 \mathrm{mg} \cdot \mathrm{kg}^{-1} \mathrm{BW}, 60 \mathrm{mg} \cdot \mathrm{kg}^{-1} \mathrm{BW}$, and $120 \mathrm{mg} \cdot \mathrm{kg}^{-1} \mathrm{BW}$ for 14 days administered 1 hour before LPS challenge decreased plasma MDA level that was dose-dependent.

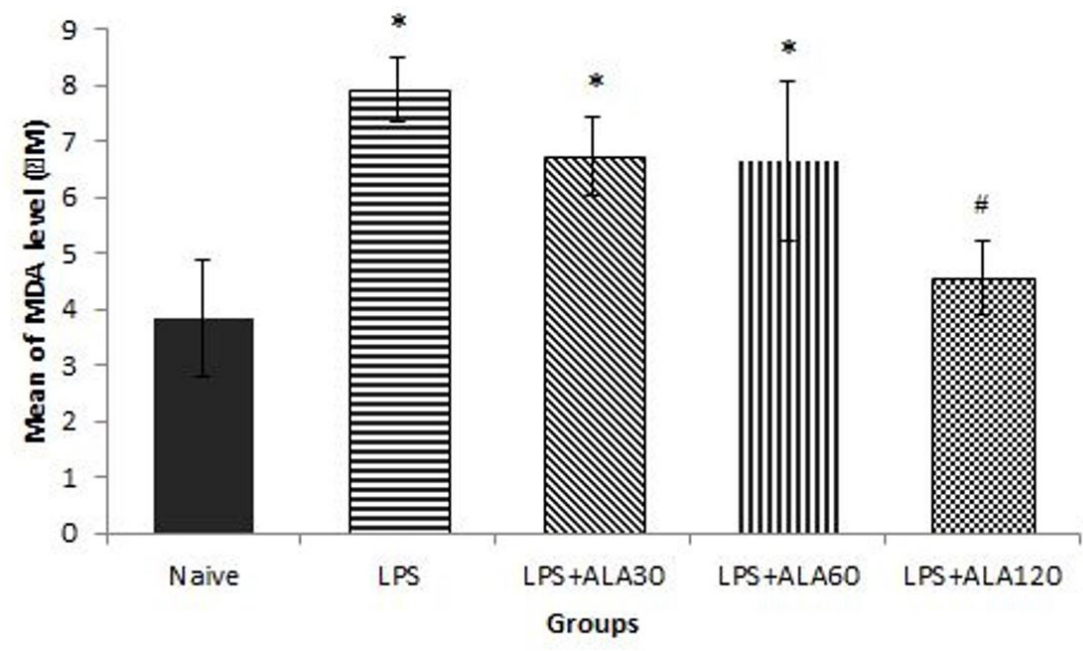

Figure 1 - Effects of ALA on plasma MDA mean concentration in rats

LPS 0.5mg.kg-1 BW i.p. was induced three times, once every three days (in 1st, 4th, and 7th day). ALA at dose 30; 60; 120 mg.kg-1 BW) was administered by oral gavage, every day for 14 days, 1 hour before LPS challenge. Plasma MDA level was measured by the TBARS method using spectrophotometer UV-Vis $\lambda 529 \mathrm{~nm}$. MDA concentration was shown as mean $\pm \mathrm{SD}(\mathrm{n}=5)$. ${ }^{*} \mathrm{p}<0.001$ vs healthy group; $\# \mathrm{p}<0.001$ vs LPS group (Tukey's multiple comparison tests). 
There was a significant difference observed at $\mathrm{p}<0.001$ (Figure 1). Tukey's tests were then performed, showing only ALA 120 mg. $\mathrm{kg}^{-1}$ BB was statistically significant compared to LPS untreated group $(p<0.001)$, but it was not significant compared to the healthy group $(p=0.677)$. The decreasing plasma MDA level, especially after 14 days of treatment with ALA would decrease oxidative stress. As a biological antioxidant, ALA has two mechanisms, direct and indirect activities. As a direct antioxidant, ALA and its reduction form, dihydrolipoic acid (DHLA) scavenge hydroxyl radicals, singlet oxygen, and hypochlorous acid. They also regenerate endogenous antioxidants such as vitamins $\mathrm{C}$ and $\mathrm{E}$, and GSH by reducing the oxidized forms. Whereas as an indirect antioxidant, both ALA \& DHLA have metalchelating properties due to dithiolane ring's activities. In vitro, lipoic acid can chelate of divalent metal ions and form stable complexes with $\mathrm{Zn}^{2+}, \mathrm{Cu}^{2+}, \mathrm{Mn}^{2+}$, and $\mathrm{Fe}^{2+}$ (Goraca et al., 2011, Rochette et al., 2015). The other study showed that preincubation of the HUVECs with ALA increased cell viability, all oxLDL effect, and decreased MDA content (Liu, 2011). In vivo, in LPSinduced model, ALA decreased tissue MDA level \& $\mathrm{H}_{2} \mathrm{O}_{2}$ in lymph, brain, heart (Goraca et al., 2011; Goraca et al., 2013). In the sepsis model, ALA balanced redox by decreasing testis MDA, NO, 8-hydroxydeoxyguanosine (8-OHdG) level (Ashour et al., 2011). It could also improve endothelial function due to reducing MDA level both in plasma and aortic tissue in a diabetic model (Ying et al., 2010), ischemic myocardial (Wang et al., 2011) and hypercholesterolemia rat (Sari et al., 2016).

\section{Effect of ALA on VCAM-1 expression}

Adhesion molecules were also essential markers of endothelial dysfunction. Several mediators, including microbial stimulation of TLRs, production of cytokines, excessive levels of ROS, or turbulent blood flow at vessel bifurcations induce the expression of VCAM-1 (Milis et al., 2011). The up-regulation of VCAM-1 is a critical step in leukocyte or monocyte migration to intima during inflammation (Wu et al., 2012). Lipopolysaccharideinduced VCAM-1 expression (Jiang et al., 2013) and leukocyte adhesion in lung tissue (Wu et al., 2012). In vitro, LPS also promoted VCAM-1 expression and other adhesion molecules in human umbilical cord vein cell (HUVEC) (Liu et al., 2012; Wu et al., 2012, Baek et al., 2018), mesangial cell (Lee et al., 2012); vascular smooth muscle cell (Meng et al., 2013); mouse glial and neuronal cultures (Leow-Dyke et al., 2012). The mechanism involves TLR-4 stimulation, then trigger

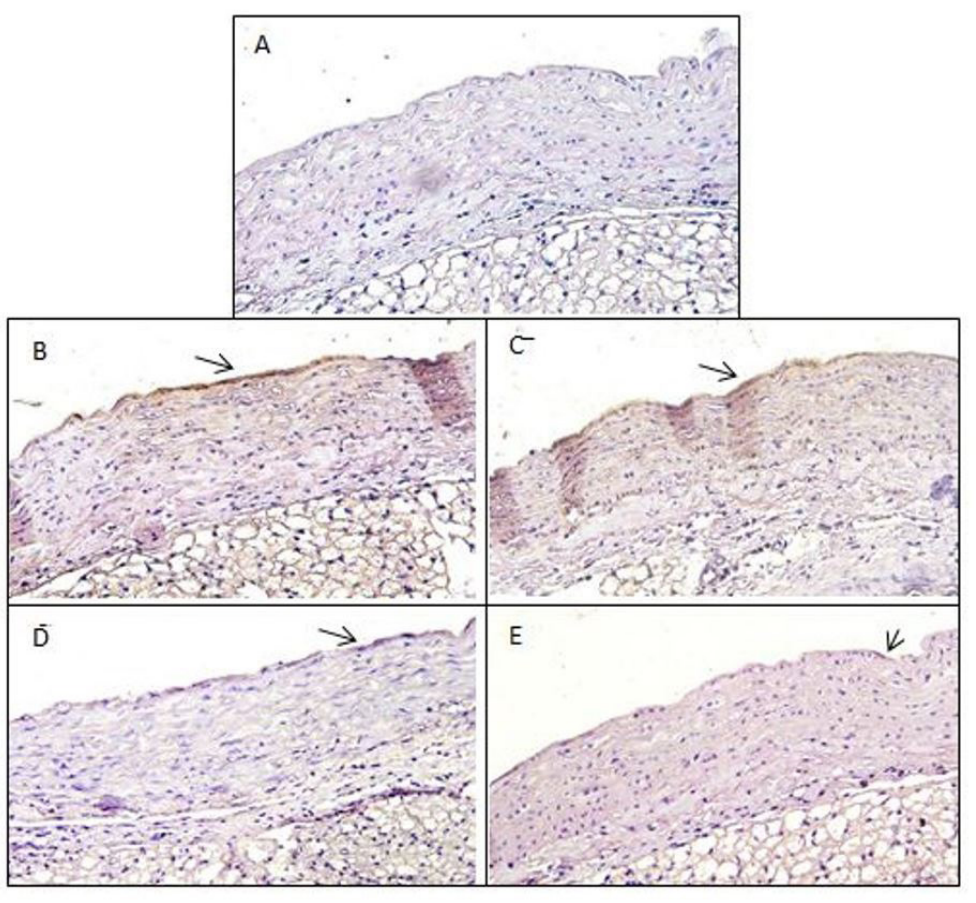

Figure 2 - Effects of ALA on VCAM-1 expression on the surface of vascular walls (endothelial cells) of rat aortic tissue (see arrow sign, $\rightarrow$ ). LPS 0.5mg.kg-1 BW i.p. was induced three times, once every three days (in 1st, 4th, and 7th day). ALA at dose 30; 60; 120 mg.kg-1 BW was given by oral gavage, every day for 14 days, 1 hour before LPS challenge. VCAM-1 expression was observed by staining aortic tissue with the VCAM-1 polyclonal antibody (1:100), magnification 400x. (A) Healthy group, (B) LPS 0.5 mg.kg-1 BW, untreated group, (C) LPS+ALA 30 mg.kg-1 BW, (D) LPS+ALA 60 mg.kg-1 BW, dan (E) LPS+ALA 120 mg.kg-1 BW. 
ROS intracellular production and MAPK \& NFKB pathway activation (Liu et al., 2012; Lee et al., 2012; Wu et al., 2012; Burger \& Touyz, 2012). Finally, they induce LOX-1 expression via TLR4/MyD88/ROS, then activated the p38MAPK-NF- $\kappa \mathrm{B}$ pathway to promotes ox-LDL endocytosis and acts as an adhesion molecular supporting endothelial-monocyte interaction (Zhao et al., 2014).

By understanding the molecular mechanism of vascular inflammation in atherosclerosis are now yielding novel target for pharmacotherapy (Rahmathulla \& Devi, 2015). Since ROS could induce VCAM-1 production and expression, antioxidants were believed as a potential agent in endothelial dysfunction by blocking its signal transduction, and VCAM-1-dependent inflammation. The signalling of VCAM-1 became a target for intervention by antioxidants or by pharmacological agents during inflammatory diseases (Mills et al., 2011), especially in cardiovascular disease.

The VCAM-1 expression on the surface of endothelial cells was determined by staining aortic tissue with rat antibody VCAM-1 (Figure 2). In a healthy group, negative staining of aortic tissue was observed (Figure 2A). Positive staining was demonstrated by dark brown (noted by black arrow) on the surface of endothelial cells from all groups threat with LPS $0.5 \mathrm{mg} \cdot \mathrm{kg}^{-1} \mathrm{BW}$. The most robust expression was shown in the untreated group (Figure 2B). The protein expression on the endothelial cell surface was attenuated after 14 days ALA administration in LPS challenge rats, depending on the dose, as illustrated in Figure 2C (ALA $30 \mathrm{mg} \cdot \mathrm{kg}^{-1} \mathrm{BW}$ ), Figure 2D (ALA $60 \mathrm{mg} \cdot \mathrm{kg}^{-1} \mathrm{BW}$ ), and Figure 2E (ALA $\left.120 \mathrm{mg} \cdot \mathrm{kg}^{-1} \mathrm{BW}\right)$. The scoring of VCAM-1 expression, which determined by the Allred system, interpreted the weak staining in all ALA treatment groups (data was not shown). Then, analysis with Kruskal-Wallis showed that ALA administration in the treatment group $(30,60$, and $\left.120 \mathrm{mg} \cdot \mathrm{kg}^{-1} \mathrm{BW}\right)$ significantly attenuated VCAM-1 expression $(\mathrm{p}<0.001)$.

This present study showed that ALA administration, as one of the potential antioxidant could attenuate VCAM1 expression. In line with this result, in vitro assays using HUVEC (Tomo et al., 2015) and homocysteine-induced injuries to human aortic endothelial cells (HAECs) ( $\mathrm{Hu}$ et al., 2016). Whereas in vivo, ALA treatment markedly and dose-dependently attenuated the expression of VCAM-1 in ovariectomized Ldlr-/- mice (Shen et al., 2018). Lipoic acid decreased oxidative stress, inhibited $\mathrm{NF}-\kappa \mathrm{B}$ activation, improved vascular reactivity, attenuated expression of adhesion molecules, especially mRNA expression of VCAM-1 in thoracic aorta of Watanabe heritable hyperlipidemic (WHHL) and also reduce atherosclerotic plaques in the abdominal aorta in rabbits (Ying et al., 2010) and atherosclerotic mice (Lee et al., 2012).

The arrangement of ALA in attenuating VCAM-1 expression involves the activation of the PI3K/Akt pathway that can negatively regulate the $\mathrm{NF \kappa B}$ activation pathway. Previous studies showed that ALA ameliorated inflammation and apoptosis in aortic tissues of aged type II diabetes rat (Bitar et al., 2010) and attenuated LPSinduced cardiac dysfunction (Jiang et al., 2013) through a PI3K/Akt-dependent mechanism. The PI3K/Akt pathway can negatively regulate the $\mathrm{NF \kappa B}$ activation pathway. Lipoic acid also inhibited $\mathrm{I} \kappa \mathrm{B} \alpha$ degradation and NFKB activation through inhibition of IKK2 rather than its antioxidant function (Ying et al., 2011). In contrast, lipoic acid as an antioxidant may also oxidize sulfhydryl groups or form mixed disulfides on proteins, thus influencing the changes in the thiol redox status of $\mathrm{NF}-\kappa \mathrm{B}$ as a redox-sensitive transcription factor (Goraca et al., 2011). The suppression of NF- $\kappa$ B will lead to a decrease in the production of pro-inflammatory genes, especially VCAM-1. Thus, the inflammation responses were also limited as the decreasing of the VCAM-1 output.

\section{CONCLUSION}

In conclusion, ALA may have a protective effect against LPS-induced endothelial dysfunction in rats and have a potential health benefit in preventing inflammatory vascular disease. However, further studies in detail are required to explore other mechanisms of ALA in preventing endothelial dysfunction.

\section{ACKNOWLEDGEMENT}

We gratefully acknowledge the support from Faculty of Pharmacy, University of Jember; Faculty of Pharmacy, Airlangga University, and The Ministry of Research, Technology and Higher Education, Indonesia of the year 2018.

\section{REFERENCES}

Allred, D.C. (2005). Assessment of prognostic and predictive factors in breast cancer by immunohistochemistry. Connection, 9, 4-5

Ashour, A.E., Abdel-Hamied, H.E., Korashy, H.M., Al-Shabanah, O.A., \& Abd-Allah, R.A. (2011). Alphalipoic acid rebalances redox and immune-testicular milieu in septic rats. Chemico Biological Interactions, 189, 198-205

Baek, N., Sim, S., \& Heo, K.S. (2018). LPS-stimulated macrophage activation affects endothelial dysfunction. 
Journal of Bacteriology and Virology, 48, 23-30

Bharadwaj, R., Mathur, K., Sharma, D., \& Sankhla, M. (2014). The Relationship between Oxidative Stress and Atherogenic Index (A.I.) in Preeclampsia. Scholars Journal of Applied Medical Sciences, 2(6D), 3092-6

Bitar, M., Ayed, A.K., Halim, S.M.A., Isenovic, E.R., \& Al-Mulla, F. (2010). Inflammation and apoptosis in aortic tissues of aged type II diabetes: Amelioration with $\alpha$-lipoic acid through phosphatidylinositol 3-kinase/Aktdependent mechanism. Life Sciences, 86, s844-53

Burger, D. \& Touyz, R.M. (2012). Cellular biomarkers of endothelial health: microparticles, endothelial progenitor cells, and circulating endothelial cells. Journal of the American Society of Hypertension, 6, 85-99

Emokpae, M.A. and Uadia, P.O. (2012). Association of Oxidative StressMarkers with Atherogenic Index of Plasma in Adult Sickle Cell Nephropathy. Anemia, 2012, $1-5$

Erridge, C., Guerrero, E.B., \& Poxton, I.R. (2002). Structure and function of lipopolysaccharides. Microbes and Infection, 4, 837-51

Favero, G., Paganelli, C., Buffoli, B., Rodella, L., \& Rezzani, R. (2014). Endothelium and its alterations in cardiovascular diseases: life style intervention. BioMed Research International, 2014, 1-28.

George, S.J., \& Lyon, C. (2010). Pathogenesis of atherosclerosis. In: George SJ, Johnson J, editors. Atherosclerosis: molecular and cellular mechanisms. 1st ed. Weinheim: WILEY-VCH Verlag GmbH \& Co

Gimbrone, M.A. \& García-Cardeña, G. (2016). Endothelial Cell Dysfunction and the Pathobiology of Atherosclerosis. Circulation Research, 118, 620-36

Gonzalo, S., Grasa, L., Arruebo, M.P., Plaza, M.A., \& Murillo. (2010). M.D. Inhibition of p38MAPK improves intestinal disturbances and oxidative stress induced in a rabbit endotoxemia model. Neurogastroenterol Motil, $22,564-72$

Goraca, A., Huk-Kolega, H., Piechota, A., Kleniewska, P., Ciejka, E., \& Skibska, B. (2011). Lipoic acid-biological activity and therapeutic potential. Pharmacological Reports, 63, 849-58

Goraca, A., Kolega, H.H., Kleniewska, P., Polañczyk, A.P., \& Skibska, B. (2013). Effects of lipoic acid on spleen oxidative stress after LPS administration. Pharmacological Reports, 65, 179-86
Jayashree, V. \& Prakash, R. (2015). Protective effect of COX inhibitors on lipopolysaccharide-induced sickness behaviour or neuroinflammation and oxidative stress in male Wistar rat. International Journal of Pharmacy and Pharmaceutical Sciences, 7, 240-5

Jiang, S., Zhu, W., Li, C., Zhang, X., Lu, T., Ding, Z., et al. (2013). $\alpha$-lipoic acid attenuates LPS-induced cardiac dysfunction through a PI3K/Akt-dependent mechanism. International Immunology, 16, 100-7

Kemenkes RI. (2012). Profil Kesehatan Indonesia 2012. Jakarta: Pusat Data dan Informasi Kemenkes RI.

Lee, I.T., Shih, R.H., Lin, C.C., Chen, J.T., \& Yang, C.M. (2012). Role of TLR4/NADPH oxidase/ROSactivated p38 MAPK in VCAM-1 expression induced by lipopolysaccharide in human renal mesangial cells. $J$ Cell Communication and Signaling, 10,1-15

Leow-Dyke, S., Allen, C., Denes, A., Nilsson O., Maysami, S., Bowie, A.G. Rothwell, N.J., \& Pinteaux E. (2012). Neuronal toll-like receptor 4 signalling induces brain endothelial activation and neutrophil transmigration in vitro. Journal of Neuroinflammation, 9, 230-10.

Liu, Y.X., Han, G.Z., Wu, T., Liu, P., Zhou, Q., Liu, K.X., \& Sun, H.J. (2011). Protective effect of $\alpha$-lipoic acid on oxidized low density lipoprotein-induced human umbilical vein endothelial cell injury. Pharmacological Reports, 63, 1180-8

Liu, X.H., Pan, L.L., Yang, H.B., Gong, Q.H., \& Zhu, Y.Z. (2012). Leonurine attenuates lipopolysaccharideinduced inflammatory responses in human endothelial cells: Involvement of reactive oxygen species and NF$\kappa \mathrm{B}$ pathways. European Journal of Pharmacology, 680, 108-14

McIlduff, C.E \& Rutkove, S.B. (2011). Critical appraisal of the use of alpha-lipoic acid (thioctic acid) in the treatment of symptomatic diabetic polyneuropathy. Therapeutics and Clinical Risk Management, 7, 377-85

Meng, Z, Yan, C., Deng Q., Gao, D.F., \& Niu, X.L. (2013). Curcumin inhibits LPS-induced inflammation in rat vascular smooth muscle cells in vitro via ROS-relative TLR4-MAPK/NF- $\mathrm{B}$ pathways. Acta Pharmacologica Sinica, 34, 901-11

Mills, J.M., Marchese, M., \& Valencia, H.A. (2011). Vascular cell adhesion molecule-1 expression and signalling during disease: regulation by reactive oxygen species and antioxidants. Antioxidants \& Redox Signaling, 15, 1-32 
Mudau, M., Genis, A., Lochner, A., \& Strijdom, H. (2012). Endothelial dysfunction: the early predictor of atherosclerosis. The Cardiovascular Journal of Africa, $23,222-31$

Munzel, T., Gori, T., Bruno, R.M., and Taddei, S. (2010). Translational medicine: Is oxidative stress a therapeutic target in cardiovascular disease?. European Heart Journal, 31, 2741-49

Rahmathulla, M.S.B. \& Devi, L.K. (2015). Advanced molecular and cell-based therapies for atherosclerosis. Asian Journal of Pharmaceutical and Clinical Research, 8, 54-9

Rochette, L., Ghibu, S., Muresan, A., \& Vergely, C. (2015). Alpha-lipoic acid: molecular mechanisms and therapeutic potential in diabetes. Journal of Physiology and Pharmacology, 93, 1021-7

Sari, D.P., Susilo, I., \& Khotib, J. (2016). The mechanism of alpha-lipoic acid on reducing the MDA level and MCP-1 expression in endothelial dysfunction of hypercholesterolemia rat (Rattus norvegicus) model. Folia Medica Indonesiana, 52, 154-159

Sawa, Y., Ueki, T., Hata, M., Iwasawa, K., Tsuruga, E., Kojima, H., et al. (2008). LPS-induced IL-6, IL-8, VCAM-1, and ICAM-1 expression in human lymphatic endothelium. Journal of Histochemistry \& Cytochemistry, 6, 97-109

Shen, D., Tian, L., Shen, T., Sund, H., \& Liu, P. (2018). Alpha-lipoic acid protects human aortic endothelial cells against $\mathrm{H}_{2} \mathrm{O}_{2}$-induced Injury and inhibits atherosclerosis in ovariectomized low-density lipoprotein receptor knock-out mice. Cellular Physiology and Biochemistry, 47, 2261-77.

Steyers, C.M. \& Miller, F.J. (2014). Endothelial Dysfunction in Chronic Inflammatory Diseases. International Journal of Molecular Sciences, 15, 1132449

Tomo, P.D., Silvestre, S.D., Cordone, V.G.P., Giardinelli, A., Faricelli, B., \& Pipino, C., et al. (2015). Centella Asiatica and lipoic acid, or a combination thereof, inhibit monocyte adhesion to endothelial cells from umbilical cords of gestational diabetic women. Nutrition, Metabolism and Cardiovascular Diseases, 25, 659-66

Vijayakumar, P.R.A., Kalshetti, S.M., Bhatt, J.K. (2014). Supplementation of a-lipoic acid in diabetic peripheral neuropathy: A prospective open-label randomized controlled trial. International Journal of Pharmacy and Pharmaceutical Sciences, 6, 90-3
Wang, H., \& Huo, Y. (2010). Adhesion molecule and atherosclerosis - Part II: Proinflammatory factor. In: George SJ, Johnson J, editors. Atherosclerosis: molecular and cellular mechanisms. 1st ed. Weinheim: WILEY-VCH Verlag GmbH \& Co. KgaA.

Wang, X., Yu, Y., Ji, L., Liang, X., Zhang, T., \& Hai, C.X. (2011). Alpha-lipoic acid protects against myocardial ischemia/reperfusion injury via multiple target effects. Food and Chemical Toxicology, 49, 2750-7.

Widlansky, M.E., \& Gutterman, D.D. (2011). Regulation of endothelial function by mitochondrial reactive oxygen species. Antioxidants \& Redox Signaling, 15, 1517-30.

World Health Organization (WHO). (2014). Cardiovascular Diseases (CVDs). Report on Factsheet No. 317. Geneva: World Health Organization. https:// www.who.int/en/news-room/fact-sheets/detail/ cardiovascular-diseases-(CVDs)

World Health Organization (WHO). (2018). Indonesia. Country Profile on Mortality and Burden of Disease: Non-Communicable Diseases. Geneva: World Health Organization. https://www.who.int/nmh/countries/idn en.pdf

Wu, Y.H., Chuang, S.Y., Hong, W.C., Lai, Y.L., Chang, Y.L., \& Pang, J.H. (2012). In vivo and in vitro inhibitory effects of a traditional Chinese formulation on LPS-stimulated leukocyte-endothelial cell adhesion and VCAM-1 gene expression. Journal of Ethnopharmacology, 140, 55- 63.

Yang, R.L., Shi, Y.H., Hao, G., \& Le, G.W. (2008). Increasing oxidative stress with progressive hyperlipidemia in human: relation between malondialdehyde and atherogenic index. Journal of Clinical Biochemistry and Nutrition, 43, 154-8

Ying, Z., Kherada, N., Farrar, B., Kampfrath, T., Chung, Y., Simonetti, O., et al. (2010). Lipoic acid effects on established atherosclerosis. Life Sciences, 86, 95-102.

Ying, Z., Kampfrath, T., Sun, Q., Parthasarathy, S., \& Rajagopalan, S. (2011). Evidence that $\alpha$-lipoic acid inhibits NF- $\mathrm{KB}$ activation independent of its antioxidant function. Inflammation Research, 60, 219-25.

Zhao, W., Ma, G., \& Chen, X. (2014). Lipopolysaccharideinduced LOX-1 expression via TLR4/MyD88/ROS activated the p38MAPK-NF-кB pathway. Vascular Pharmacology, 63, 162-72. 